\title{
NeW Design of LEAKY WAVE ANTENNa BASED ON SIW TECHNOLOGY FOR BEAM STEERING
}

\author{
Souaad Doucha ${ }^{1}$ and Mehadji Abri ${ }^{1}$ \\ ${ }^{1}$ Telecommunication Laboratory \\ Electrical and Engeneering Departement, Faculty of Technology, \\ University of Abou-Bekr Belkaïd-Tlemcen \\ BP 230, Chetouane, 13000 Tlemcen- Algeria. \\ souadtelecomegmail.com \\ abrim2002@yahoo.fr
}

\begin{abstract}
This paper presents the results of an investigation of a new version of a leaky wave antenna that is based on a substrate integrated waveguide (SIW). The structure of SIW is composed of two rows of cylinders between metal plates; it can be easily produced by the standard method PCB" circuit" or LTCC method, the antenna is designed so that it can radiate in C-band. The direction of the main lobe of the antenna radiation pattern can be steered by changing the frequency in the band from backward direction to forward direction; the effect of increasing the number of slot arrays has also been analyzed to study the effect on radiation patterns. The numerical simulations have been performed using a commercial CST Microwave studio.
\end{abstract}

\section{KEY WORDS}

Leaky wave antenna, substrate integrated waveguide, slots, C-band, CST, moment's method.

\section{INTRODUCTION}

A leaky-wave antenna or LWA has been widely used in aerospace applications for many years. They are a guided structures using leakage wave propagation as a radiation mechanism. LWA based of closed waveguides require few means of calculations in the design are achievable with simple fabrication techniques and are therefore suitable for mass production.

The first substrate integrated waveguides was reported by Shigeki in 1994. The main purpose of the use of this new type of structure is increase the integration density while reducing the production costs; Shigeki demonstrated that two rows of cylinders between metal plates can confine electromagnetic fields as well as a rectangular waveguide. Substrate integrated waveguide (SIW) technology has been studied recently and has by now become a widely applied technique in planar microwave circuit design [1-4]. These structures have many advantages such as: mass production, high Quality factor, and low losses [5 -10].

An SIW LWA concept was proposed in [11], this antenna radiates energy through the SIW side. One of the applications of leaky-wave antenna based on substrate integrated waveguide (SIW) is 
that the antenna radiates in one main beam that can be steered from the Back-Fire to the End-Fire by changing the frequency [12-13].

In this paper, we design a SIW component operating in C-band for TE10 mode with CST Microwave Studio ${ }^{\circledR}$ commercial software's. To validate the obtained results, a comparison will be made using the rigorous Moment method of Momentum Software. The design procedures begins by extracting the equivalent width guide and then calculate the width of SIW, by the following formulas design after adapt other parameters such as diameter and the distance between the vias, and for transit SIW to microstrip we use the equations of impedance matching. After that, we designed a leaky-wave antenna based on substrate integrated waveguide (SIW) with transverse slots, the antenna radiates one main beam that can be steered from the backward to the forward direction by changing frequency, and finely we increase the number of slot to study the radiation patterns effect.

In the present work, numerous simulation results will be carried out, and the properties of the antennas in matching and radiation will be presented.

\section{Substrate integrated WaVeguide Parameters}

The SIW dimensions choice must be done carefully in order to get desired specifications. In this case, the two plain perfect conductors walls are replaced by metallic posts, cylinders must be the closest possible to tend towards a rectangular waveguide filled with dielectric. The cutoff frequency in case of a rectangular waveguide is given by:

$$
f_{c}=\frac{c}{2 \pi} \sqrt{\left(\frac{m \pi}{a}\right)^{2}+\left(\frac{n \pi}{b}\right)^{2}}
$$

Where:

The cut off frequency of the fundamental mode $\mathrm{TE}_{10}$ mode is determined by the following formula:

$$
f_{c}=\frac{c}{2 a}
$$

For DFW wave guide the dimension $a_{\mathrm{d}}$ can be calculated as:

$$
a_{d}=\frac{a}{\sqrt{\varepsilon}}
$$

The SIW waveguide width is written as [14]:

$$
a_{s}=a_{d}+\left(\frac{d^{2}}{0.95 s}\right)
$$

Where:

$d$ : diameter of the via

$s$ : distance between the vias

For SIW design, the following two conditions are required:

$$
\frac{\lambda_{g}}{5}<d
$$


The guided wavelength is determined by the following formula:

$$
\lambda_{g}=\frac{2 \pi}{\sqrt{\frac{(2 \pi f)^{2} \varepsilon_{r}}{c^{2}}-\left(\frac{\pi}{a}\right)^{2}}}
$$

The configuration for the single layered SIW waveguide is shown in Figure 1.

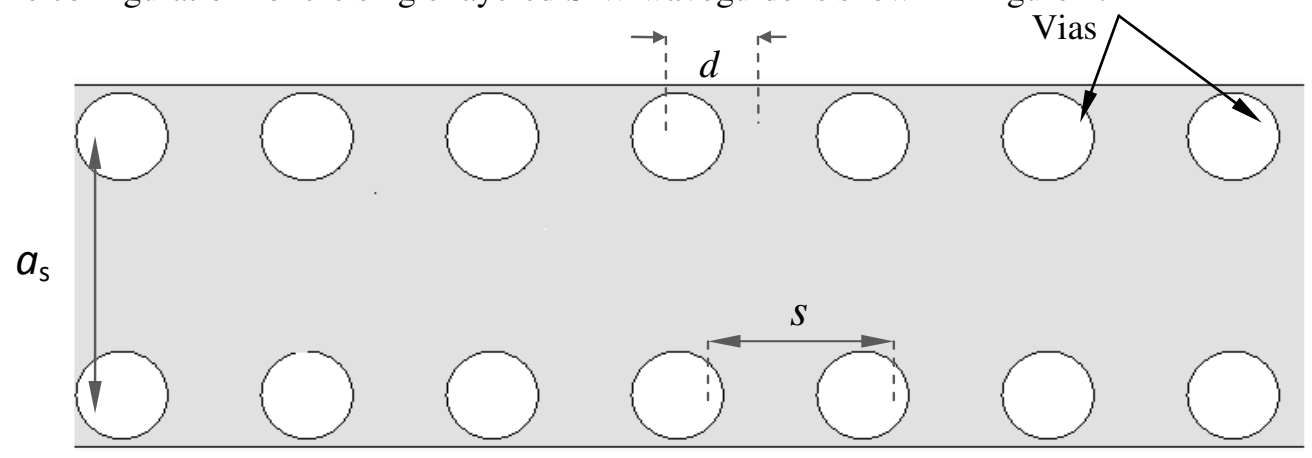

Figure 1. Layout of the symmetrical SIW waveguide parameters.

\section{FEed DESIGN}

In order to make an SIW working for C-band applications we investigated these equations the cutoff frequency of $\mathrm{TE}_{10}$ mode in SIW is selected about $5.7 \mathrm{GHz}$ with the following parameters on Arlon $\mathrm{Cu}$ 2331x (lossy), with dielectric constant of $\varepsilon \mathrm{r}=2.33$ and $\operatorname{tang} \delta=0.0013$. These parameters are used to construct SIW by using CST Microwave Studio software. The result of the simulation for the cutoff frequency $5.7 \mathrm{GHz}$ is given by the Figure 2, it is clear that the transmission between $[3-5.7 \mathrm{GHz}]$ is impossible before the cutoff frequency which is $5.7 \mathrm{GHz}$ as theoretically calculated. In this case, the transmission between $[5.7-7.5 \mathrm{GHz}]$ is low and this is due to the poor adaptation of the guide.

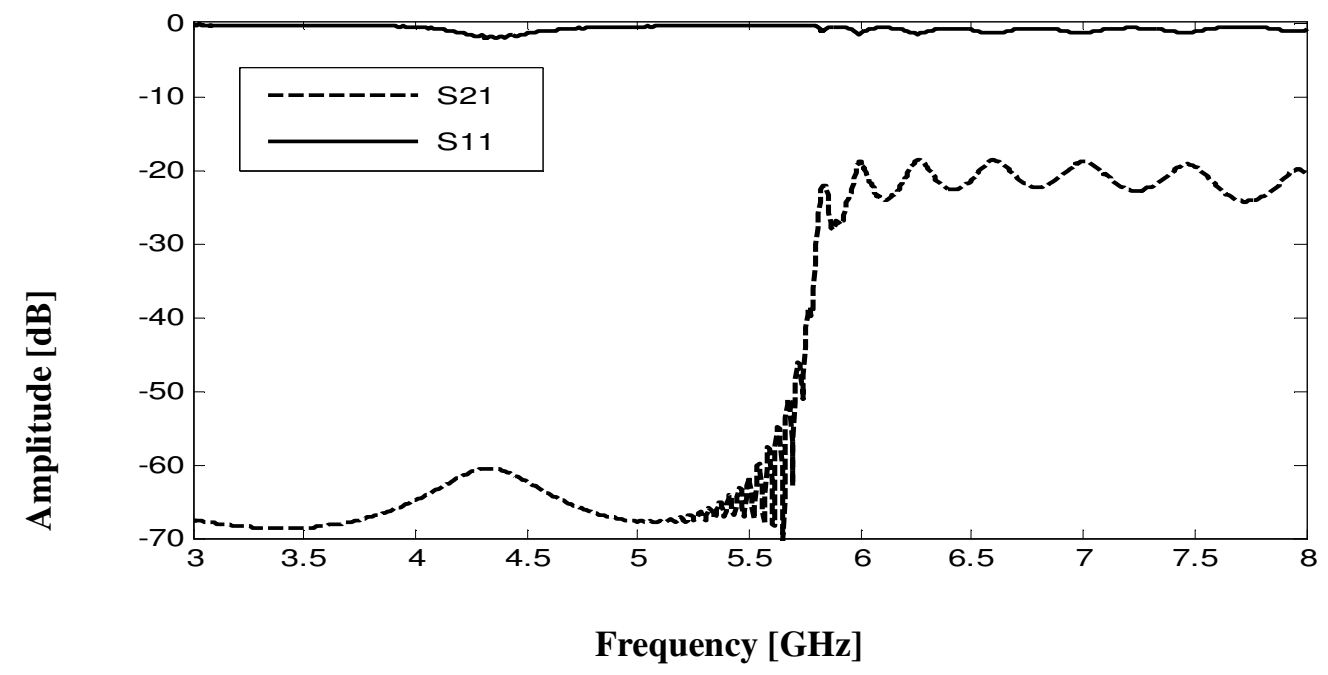

Figure 2. The reflected power and the transmission coefficient of the SIW waveguide. The SIW waveguide parameters are set to: $a s=21.5 \mathrm{~mm}, \mathrm{~d}=3.65 \mathrm{~mm}, \mathrm{~s}=14.7 \mathrm{~mm}, \mathrm{~b}=0.508 \mathrm{~mm}$. 


\section{MICROSTRIP TRANSITION LINES IN SUBSTRATE INTEGRATED WAVEGUIDE}

Once the SIW is designed, it is necessary to have a transition to a transmission line to ensure a perfect adaptation. The parameters need to be carefully chosen to achieve an optimized design. The microstrip line is one of the most used in the conception of the microwave systems transmission lines.

This transition contains two main parameters, the original width $\mathrm{W}_{0}$, the final width $\mathrm{W}$ of the profile line. The initial width of the microstrip line $\mathrm{W}_{0}$ must be calculated to obtain the desired characteristic impedance. This width is generally selected for a characteristic impedance of 50 $\mathrm{Ohm}$. For calculating the width W, it is necessary to calculate the impedance of SIW guide, which is given by the following formula.

$$
Z_{p i}=Z_{T E} \frac{\pi^{2} b}{8 a_{s}}
$$

For the calculation of the guide impedance, it is also necessary to calculate the wave impedance of TE mode, which is given by (9):

$$
Z_{T E}=j \omega \frac{\mu}{\gamma}=\omega \frac{\mu}{\beta}=\sqrt{\frac{\mu}{\varepsilon}} \times \frac{\lambda_{g}}{\lambda}
$$

The calculated parameters are used to construct a taper by using ADS (advanced design system) software. The simulation result of taper and the structure after optimization is shown in Figure 3.

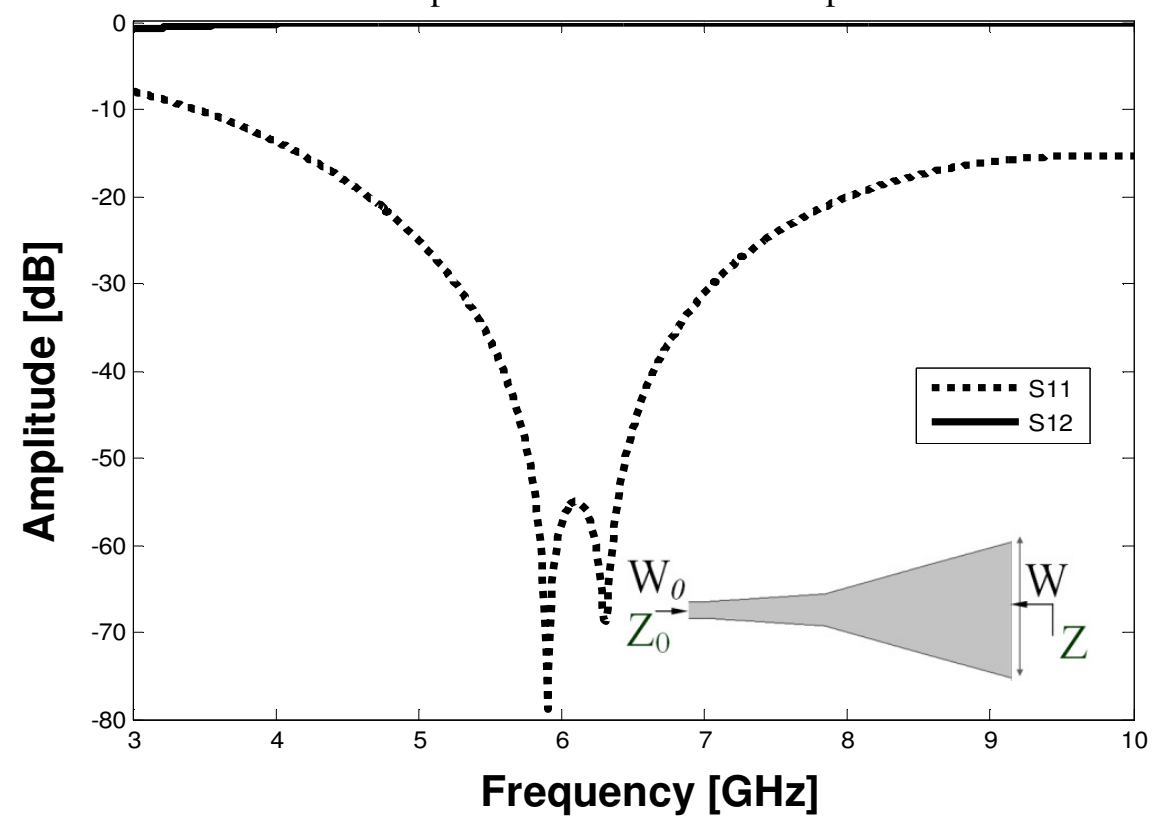

Figure 3. The return loss and the transmission coefficient of the transition and the geometrical layout of optimized taper. The parameters are set to: $Z 0=50 \mathrm{ohm}, Z=9.66 \mathrm{ohm}, \mathrm{w} 0=1.45 \mathrm{~mm}, \mathrm{w}=11.63 \mathrm{~mm}$. 
According to the Figure 3, we see an excellent adaptation between 5.7-7.5 GHz. This is necessary to avoid a drop in $\mathrm{dB}$ when inserting transition guide with SIW. The physical transition structure of microstrip line with the guide SIW is shown in Figure 4.

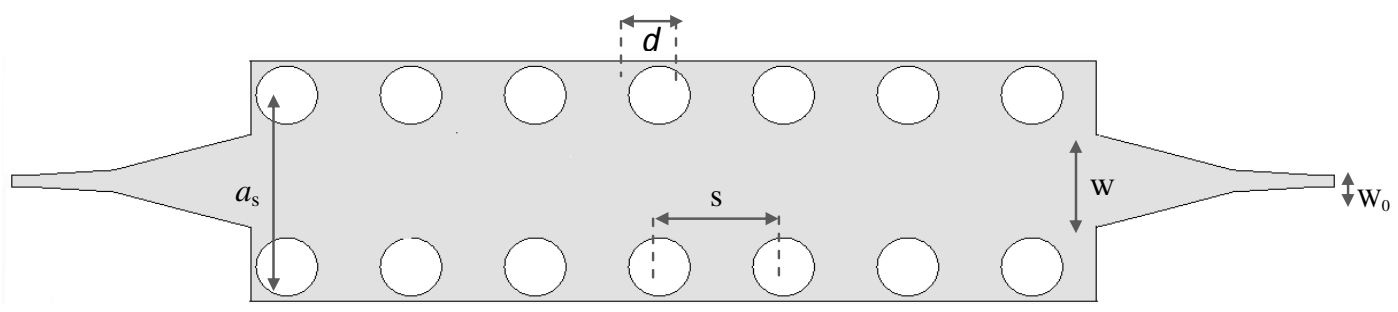

Figure 4. Topology of transition with SIW guide.

Reflected power and the transmission coefficient of the transition topology with SIW guide is obtained by simulation using CST and Momentum software's between [5.7-7.5GHz] are shown respectively in the Figure 5 and Figure 6.

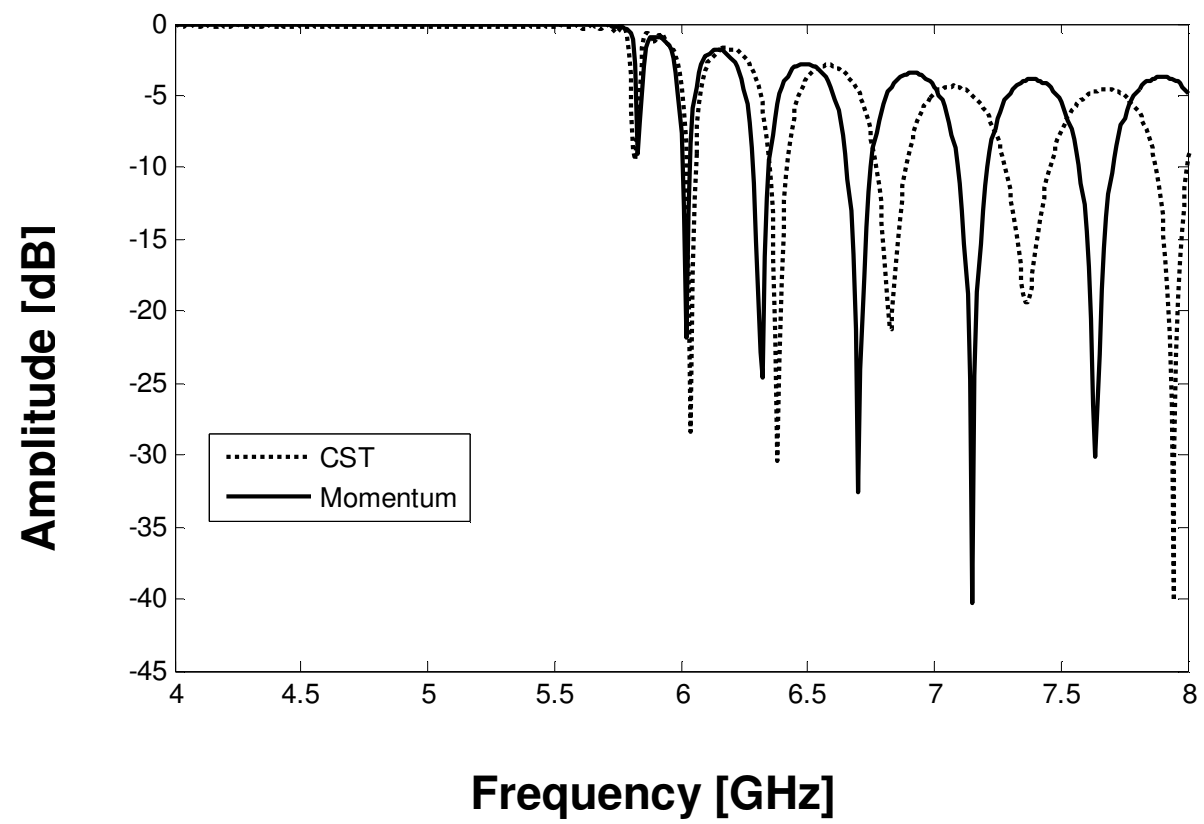

Figure 5.Return loss of the SIW guide presented in Figure 4 simulated with CST and Momentum software's. The SIW waveguide parameters are set to: $a s=21.5 \mathrm{~mm}, \mathrm{~d}=3.65 \mathrm{~mm}, \mathrm{~s}=14.7 \mathrm{~mm}, \mathrm{~b}=$ $0.508 \mathrm{~mm}$. 


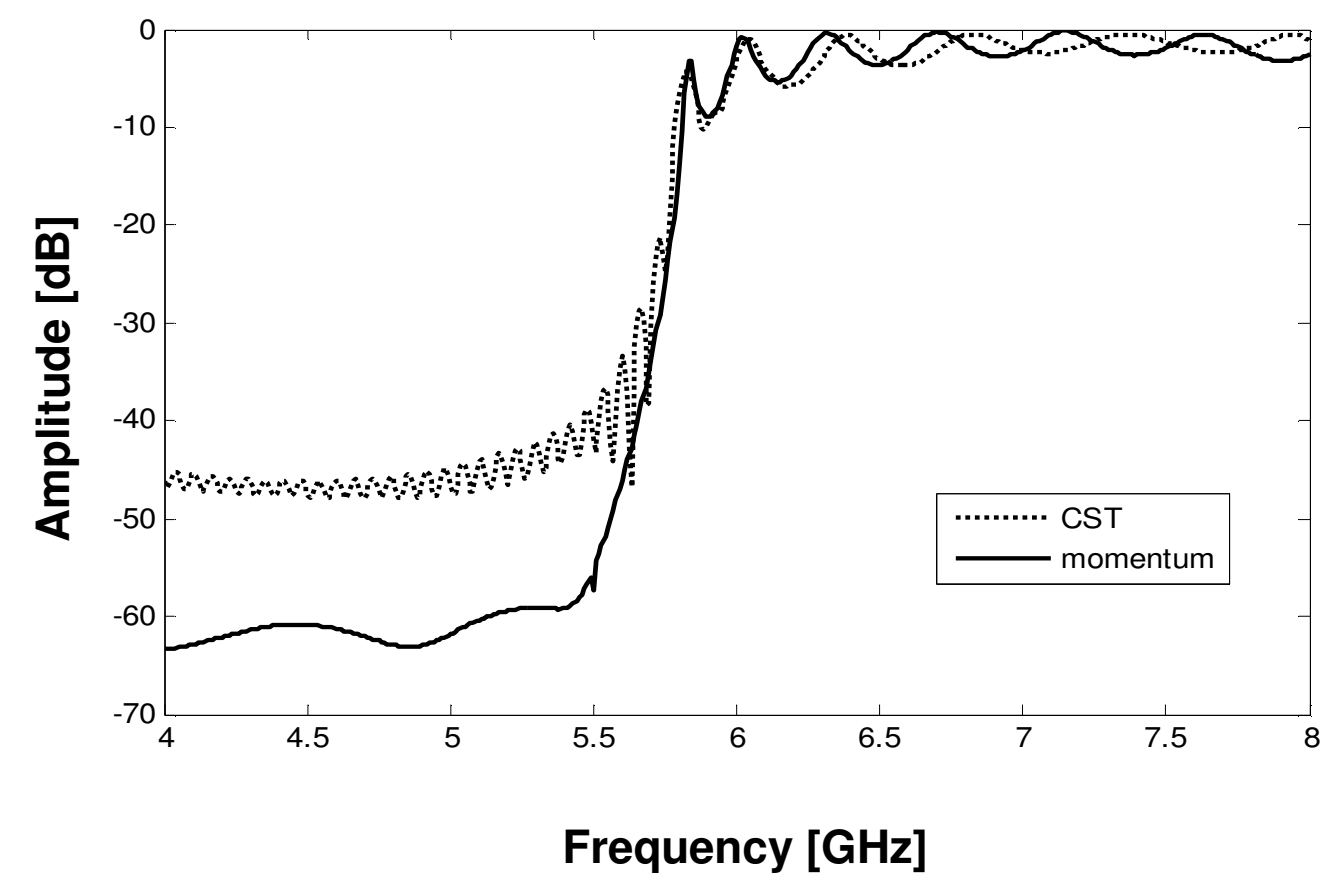

Figure 6. Transmission coefficient $S_{12}$ of the waveguide.

Notice from Figure 5 and 6that the both CST and Momentum simulation results agrees well with the calculated cutoff frequency of $5.7 \mathrm{GHz}$. A remarkable improvement of the return loss has been achieved and several resonant frequencies appears in the range [5.7-8.0 GHz] with amplitude less than $-20 \mathrm{~dB}$.

\section{SIW LEAKY-WAVE ANTENNA DESIGN}

The geometry, parameters, top view for the proposed planar leaky-wave antenna are shown in Figure 7, the antenna under consideration is basically a wave guiding structure that possesses a mechanism that permits it to leak power all along its length. In this paper we construct a LWA based on SIW as shown in Figure 7.
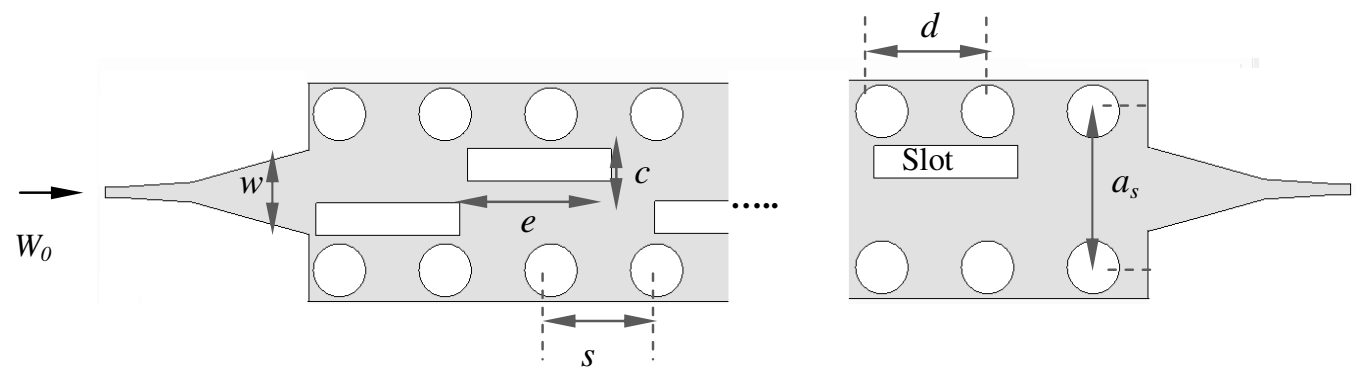

Figure 7.Top view of the proposed leaky-wave antenna based on Substrate integrated waveguide with $\mathrm{d}=3.65 \mathrm{~mm}, \mathrm{~s}=14.7 \mathrm{~mm}$, as $=21.5 \mathrm{~mm}, \mathrm{w}=11.63 \mathrm{~mm}$ and $\mathrm{w} 0=1.45 \mathrm{~mm}$. 
The dimensions of the slots are important for the antenna to behave as a slot antenna. The dimensions of the slots can be obtained with the help of the following relations.

$$
e=\frac{\lambda_{0}}{\sqrt{2\left(\varepsilon_{r}+1\right)}}
$$

Dimension of c doesn't matters much but should be less than half of e. The gap between centre to centre of slots has been considered as ëg $/ 2$.

The final optimal physical structure as obtained after a microstrip to SIW transition with 4 uniform slots having the same size and the S-parameter of the LWA based in SIW are shown in Figure 8 .

The radiation patterns in 3D representation and in polar coordinates of only one-port LWA are depicted respectively in Figure 9 and Figure 10

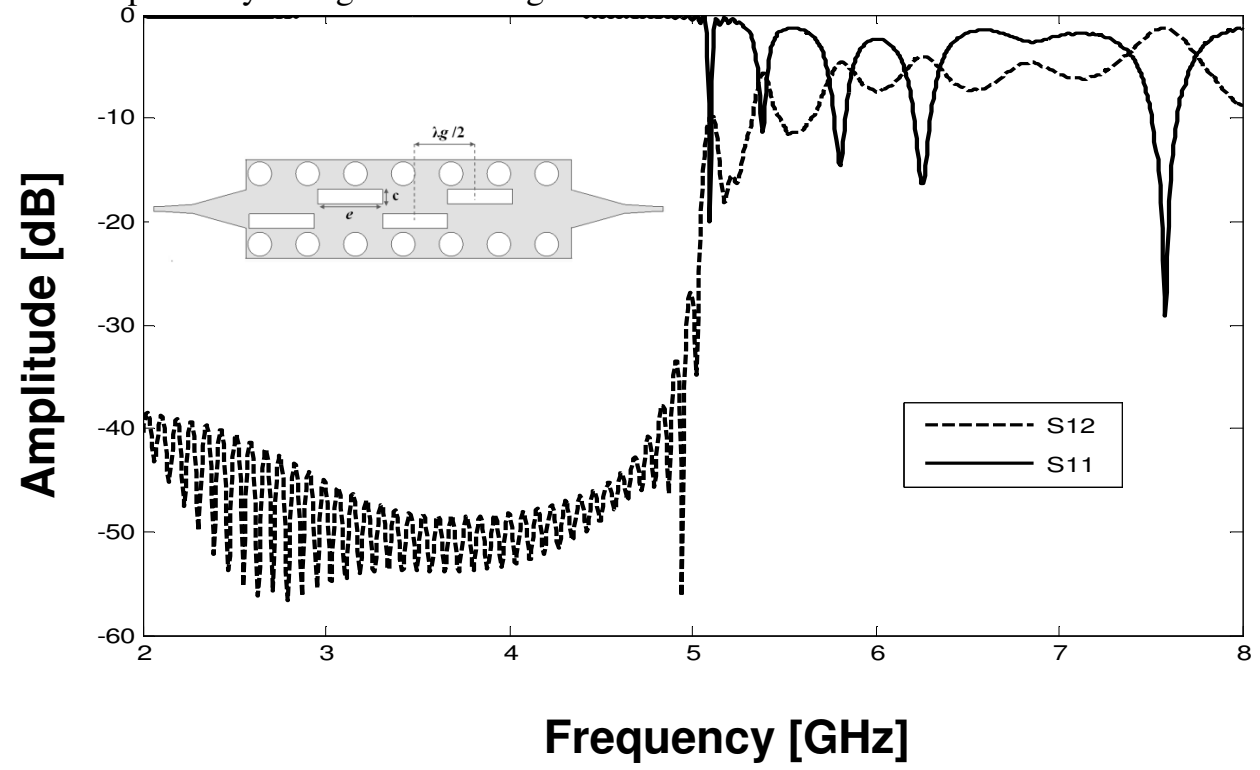

Figure 8. S-parameter of the LWA based in SIW in band [ $5.7-7.5 \mathrm{GHz}$ ], the antenna has been found to resonate at $5.5 \mathrm{GHz}$. Dimension of slots of leaky-wave antenna based on substrate integrated waveguide with: $\mathrm{e}=20 \mathrm{~mm}, \mathrm{c}=4.5 \mathrm{~mm}$ and $\lambda \mathrm{g}=22 \mathrm{~mm}$. 

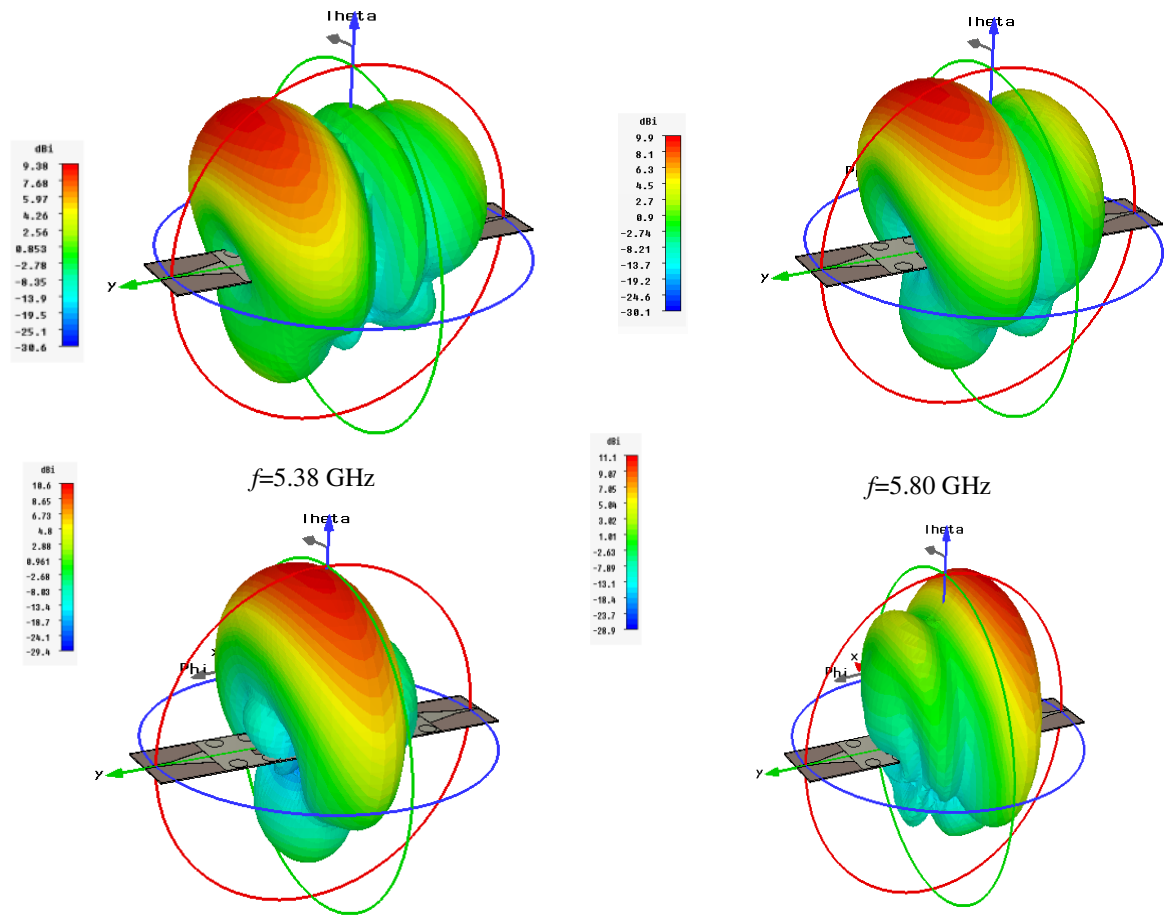

$f=6.25 \mathrm{GHz}$

$f=7.50 \mathrm{GHz}$

Figure 9.3D radiation patterns obtained of LWA with changing frequency. $f=5.38 \mathrm{GHz}$ with Main Lobe Direction $\mathrm{MLD}=-37^{\circ}, f=5.8 \mathrm{GHz}$ with $\mathrm{MLD}=-22^{\circ}, f=6.25 \mathrm{GHz}$ with $\mathrm{MLD}=8^{\circ}$ and $f=7.5 \mathrm{GHz}$ with MLD $=17^{\circ}$.

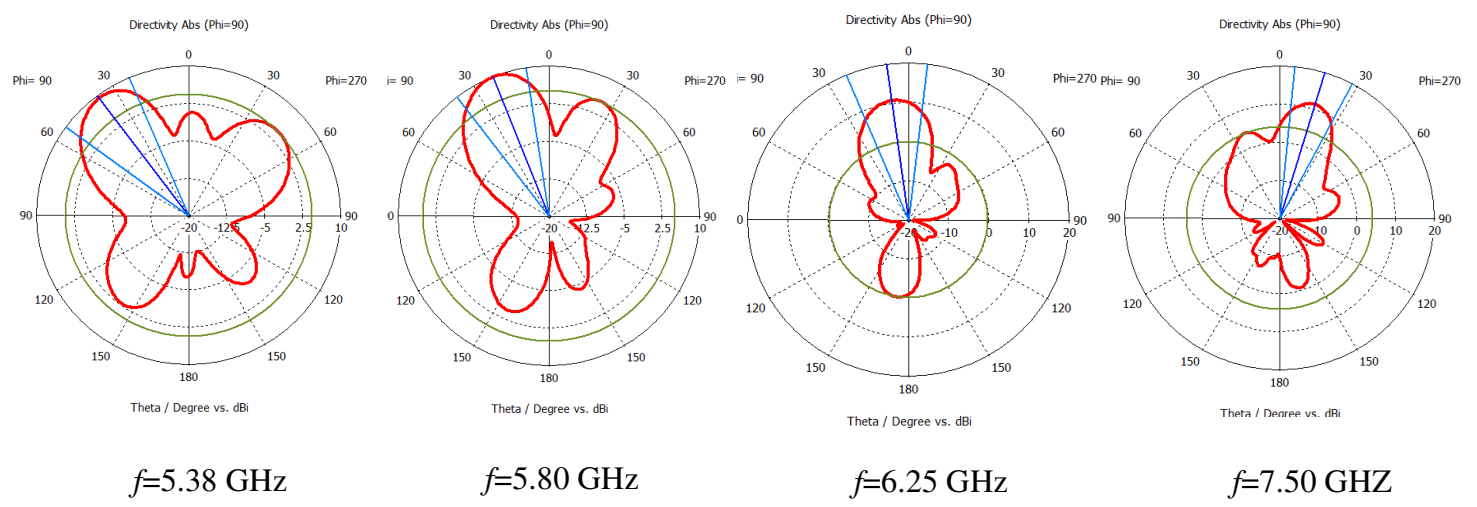

Figure 10. Radiation patterns in polar coordinates obtained of LWA with changing frequency. $\mathrm{f}=5.38 \mathrm{GHz}$ with Main Lobe Direction $\mathrm{MLD}=-37^{\circ}, f=5.8 \mathrm{GHz}$ with $\mathrm{MLD}=-22^{\circ}, f=6.25 \mathrm{GHz}$ with $\mathrm{MLD}=8^{\circ}$ and $f=7.5$ $\mathrm{GHz}$ with $\mathrm{MLD}=17^{\circ}$.

From Figure 9 and Figure 10 the beam directions are $-37^{\circ},-22^{\circ}, 8^{\circ}$ and $17^{\circ}$ calculated respectively the frequencies $5.38,5.8 \mathrm{GHz}, 6.25 \mathrm{GHz}$ and $7.5 \mathrm{GHz}$. The scanning is assured using 
this technique around the broadside direction $\left(\theta=0^{\circ}\right)$. This phenomenon is well shown in polar plot.

Our next objective has been to increase the number of slot to study the effect on radiation patterns; the LWA with nine uniform slots has been shown in Figure 11.

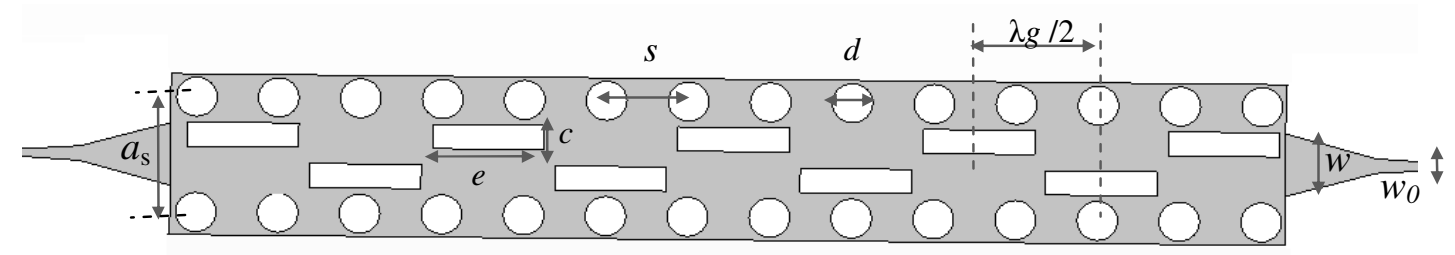

Figure 11. Leaky-wave antenna based on substrate integrated waveguide with 9 slots; $\mathrm{e}=20 \mathrm{~mm}, \mathrm{c}=4.5$ $\mathrm{mm}, \lambda \mathrm{g}=22 \mathrm{~mm}, \mathrm{~d}=3.65 \mathrm{~mm}, \mathrm{~s}=14.7 \mathrm{~mm}$, as $=21.5 \mathrm{~mm}, \mathrm{w}=11.63$ and $\mathrm{w} 0=1.45 \mathrm{~mm}$.

The radiation efficiency of one-port LWA with 9 slots is plotted in figure 12 .

According to the Figure 12 there is no great deference in main lobe direction between LWA with four uniform slots and LWA with nine uniform slots but the last one is more directive, to better observe this difference, a comparison has been made between the two antennas in term of half power beam width (HPBW).

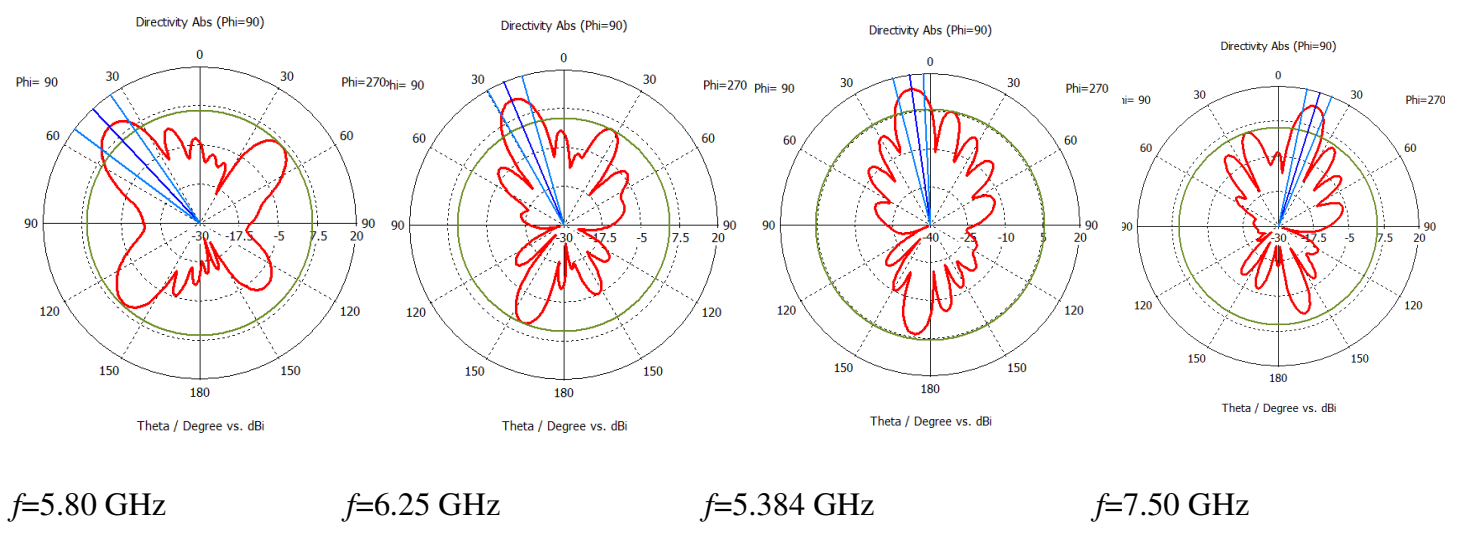

Figure 12. Radiation Patterns obtained of LWA with 9 slots with changing frequency; $f=5.384$ with main lob direction $=-43^{\circ}, f=5.8 \mathrm{GHz}$ with $\mathrm{MLD}=-23^{\circ}, f=6.25 \mathrm{GHz}$ with $\mathrm{MLD}=8^{\circ}$ and $f=7.5 \mathrm{GHzwith} \mathrm{MLD}=17^{\circ}$.

The following table shows the directivity of LWA with four and nine uniform slots:

Table. Antennas half power beam width HPBW obtained at different frequencies.

\begin{tabular}{|c|c|c|}
\hline Frequency [GHz] & $\begin{array}{c}-\mathbf{3 ~ d B ~ H P B W} \text { of LWA } \\
\text { with } 4 \text { slots }\left[{ }^{\circ}\right]\end{array}$ & $\begin{array}{c}-3 \text { dB HPBW of LWA } \\
\text { with } 9 \text { slots }\left[{ }^{\circ}\right]\end{array}$ \\
\hline 5.38 & 34.40 & 18.40 \\
\hline 5.80 & 28.9 & 14.00 \\
\hline 6.25 & 29.60 & 11.80 \\
\hline 7.50 & 22.30 & 10.50 \\
\hline
\end{tabular}


Notice from the Table, an improvement in the half power beam width has been recorded at different frequencies, the radiation patterns becomes more directing with $60^{\circ}$ ie from $-37^{\circ}$ to $17^{\circ}$ scanning angle for the antenna containing four uniform slots and $54^{\circ}$ ie from $-43^{\circ}$ to $17^{\circ}$ scanning angle.

\section{CONCLUSION}

In this paper a novel type of substrate integrated waveguide leaky wave antenna operating in the band [5.7-7.5 GHz] has been presented. First of all, based on rectangular waveguide theory, specific design rules of SIW for the design of via-hole array and effective width were reviewed. The cut off frequency was deliberately selected to avoid higher-order modes. The proposed antenna has good performance in array surroundings. A stable radiation pattern and wide usable bandwidth of the array are obtained using these types of LWA antennas. These antennas are well matched and more directing. Large scanning angle has been obtained for these antennas since the HPBW is great than $54^{\circ}$. Several simulation results are carried out, and the properties of the antennas are presented.

\section{REFERENCES}

[1] Shen W, Yin WY, and Sun XW. Miniaturized Dual-Band Substrate Integrated Waveguide Filter with Controllable Bandwidths. IEEE Microw and wireless compolett; 2011, 21: 418-420.

[2] Cassivi Y, Perregrini L, Arcioni P, Bressan, WuMK, Conciauro G.Dispersion characteristics of substrate integrated rectangular waveguide. IEEE MicroWir Compo Lett; 2002, 12: 333-335.

[3] Xu F, Wu K. Guided-Wave and Leakage Characteristics of Substrate Integrated Waveguide. IEEE Trans on MTT; 2005, 53: 66-73.

[4] Xu F, Jiang X, Wu K.Efficient and accurate design of substrate integrated waveguide circuits synthesized with metallic via-slot arrays. IET Microw Antennas Propag; 2008, 2: 188-193.

[5] Kim DY, Chung W, Park C, Lee S, Nam S. Design of a $45^{\circ}$ Inclined SIW Resonant Series Slot Array Antenna for Ka-Band. IEEE Antand Wir Propag Lett; 2011, 10: 2011.

[6] Yan L, Hong W, Hua G., Chen J, Wu K, and Cui TJ. Simulation and experiment on SIW slot array antennas. IEEE Microwand Wir Compo Lett; 2004, 14, 446-448.

[7] Lu HC, Chu TH. Equivalent circuit of radiating longitudinal slots in substrate integrated waveguide. IEEE AP-S Int Symp Dig; 2004: 2341-2344.

[8] Rayas-Sanchez JE, Gutierrez-Ayala V.A General EM-Based Design Procedure for Single-Layer Substrate Integrated Waveguide Interconnects with Microstrip Transitions. IEEE MTT-S Int Microwave Symp Dig; 2008: 983-986.

[9] Wen-Chung Liu, and Chih-Sheng Chen, Design of Missile-Mounted Siw Antenna With High Directivity for Data Transmission, Progress In Electromagnetics Research C, Vol. 38, 79-88, 2013.

[10] Sourav Moitra, Asish Kumar Mukhopadhyay \& Anup Kumar Bhattacharjee, Ku-Band Substrate Integrated Waveguide (SIW) Slot Array Antenna for Next Generation Networks, Volume 13 Issue 5, 2013.

[11] Chen IYu, Wang CJ, Jou CF. Substrate Integrated Waveguide Leaky-Wave Antenna: Concept and Design Considerations. Asia Pacific Microwave Conference, 2005:4-7.

[12] Tang XJ, Xiao SQ, Wang BZ, Wang J. A 60-GHz Wideband Slot antenna Based on Substrate Integrated Waveguide Cavity. Int J Infrared Milli Waves; 2007, 28:275-281.

[13] Dong Y, Itoh T. Composite right left-handed substrate integrated waveguide leaky-wave antennas. 39th European Microwave Conference; 2009.

[14] Chen X, Hong W, Cui T, Chen J and Wu K. Substrate Integrated Waveguide (SIW) Linear Phase Filter. IEEE Microwave and Wireless Components Letters; 2005, 15, 2005. 